\title{
Previous creatinine levels safely predict amantadine dose for influenza A outbreak control
}

\author{
Jane A Buxton MBBS FRCPC ${ }^{1,2}$, Danuta M Skowronski MD FRCPC ${ }^{1}$, Helen Ng BSc ${ }^{1}$, \\ Steve A Marion MD FRCPC ${ }^{3}$, Michele Williams RN ${ }^{1}$, Anna Forbes MD FRCPC ${ }^{4}$, \\ Arlene King MD FRCPC ${ }^{1}$, Jamie Hockin MD MSc ${ }^{2}$
}

\begin{abstract}
JA Buxton, DM Skowronski, H Ng, et al. Previous creatinine levels safely predict amantadine dose for influenza A outbreak control. Can J Infect Dis 2001;12(5):285-288.

BACKGROUND: Amantadine, an antiviral agent, is the only drug currently approved in Canada for prophylaxis of influenza A virus infection. To minimize side effects, the amantadine dose is adjusted for age and estimated creatinine clearance $(\mathrm{CrCl})$ based on plasma creatinine $(\mathrm{Cr})$ levels. As amantadine is used more frequently for influenza A outbreak control in care facilities for elderly people, physicians are increasingly called on to prescribe it for residents and to consider the necessity of requesting plasma Cr levels.

OBJECTIVE: To determine whether previous $\mathrm{Cr}$ levels are predictive in estimating current $\mathrm{CrCl}$ and safe amantadine dose determination.

DESIGN AND SETTING: Residents' charts were reviewed in two facilities in Vancouver, British Columbia. CrCl estimated using previous or current $\mathrm{Cr}$ results, current weight and age, as well as recommended amantadine doses based on Canadian National Advisory Committee on Immunization guidelines, were studied.

RESULTS: 165 charts with Cr results in March 1998 were included; 122 had results before March 1998, and $103 \mathrm{had} \mathrm{Cr}$ results after March 1998. Pearson's correlation coefficient for $\mathrm{CrCl}$ estimated from current and previous $\mathrm{Cr}$ values was 0.929 for results less than six months previously, 0.974 for six to 12 months previously and 0.952 for 12 to 18 months previously. The same or a more conservative dose of amantadine was predicted in $92 \%$ of cases when using a Cr result taken within the previous year and in $76 \%$ of cases when using a $\mathrm{Cr}$ result taken 12 to 18 months previously.

CONCLUSION: In long term care facilities, Cr levels measured up to 12 months previously can usually safely be used to estimate $\mathrm{CrCl}$. Using previous $\mathrm{Cr}$ results permits advance preparation of doctor's orders for amantadine prophylaxis and avoids repeating $\mathrm{Cr}$ testing on every resident when an outbreak occurs, reducing related staff time and cost.
\end{abstract}

Key Words: Amantadine hydrochloride; Care facilities; Creatinine clearance; Influenza; Plasma creatinine; Prophylaxis

Pour le résumé, voir page suivante

\footnotetext{
${ }^{1}$ British Columbia Centre for Disease Control, Vancouver, British Columbia; ${ }^{2}$ Field Epidemiology Training Program, Laboratory Centre for Disease Control, Health Canada, Ottawa, Ontario; ${ }^{3}$ Department of Health Care and Epidemiology, University of British Columbia; ${ }^{4}$ Consultant Geriatrician, Vancouver, British Columbia

Correspondence and reprints: Dr Danuta Skowronski, Epidemiology Services, British Columbia Centre for Disease Control Society, 655 West 12th Avenue, Vancouver, British Columbia V5Z 4R4. Telephone 604-660-6061, fax 604-660-0197. e-mail danuta.skowronski@bccdc.hnet.bc.ca

Received for publication October 16, 2000. Accepted March 30, 2001
} 


\section{Les taux antérieurs de créatinine sont de bons prédicteurs des doses d'amantadine contre les flambées de grippe $A$}

CONTEXTE : L'amantadine, un antiviral, est le seul médicament actuellement approuvé au Canada pour lutter contre l'infection au virus de la grippe A. Pour minimiser les effets secondaires, la dose d'amantadine est ajustée en fonction de l'âge et de la clairance de la créatinine ( $\mathrm{ClCr}$ ) établie d'après les taux de créatinine plasmatique ( $\mathrm{Cr}$ ). Lamantadine étant utilisée plus fréquemment dans la lutte contre la grippe A dans les établissements de soins pour personnes âgées, les médecins doivent de plus en plus souvent en prescrire aux résidents et donc envisager un contrôle des taux de $\mathrm{Cr}$ plasmatique.

OBJECTIF : Déterminer si les taux antérieurs de Cr ont une valeur prédictive pour évaluer la ClCr actuelle et établir une dose sûre d'amantadine.

MODÈLE ET CONTEXTE : Les dossiers des résidents de deux établissements de Vancouver, en Colombie-Britannique, ont été étudiés, en tenant compte de la $\mathrm{ClCr}$ estimée d'après les taux de $\mathrm{Cr}$ antérieurs ou actuels, de l'âge et du poids, de même que des doses d'amantadine recommandées dans les lignes directrices du Comité consultatif national sur l'immunisation du Canada.

RÉSULTATS : 165 dossiers indiquant les résultats de Cr en mars 1998 ont été inclus, dont 122 comprenaient des résultats de $\mathrm{Cr}$ antérieurs à mars 1998 et 103 postérieur à mars 1998. Le coefficient de corrélation de Pearson pour la ClCr estimée d'après les valeurs antérieures et présentes de $\mathrm{Cr}$ était de 0,929 pour les résultats datant de moins de six mois, de 0,974 pour les 6 à 12 mois précédents et de 0,952 pour les $12-18$ mois précédents. Une dose identique ou moindre d'amantadine a été prédite dans $92 \%$ des cas lorsqu'on utilisait un résultat de Cr obtenu depuis moins d'un an et dans $76 \%$ des cas lorsque le résultat remontait à $12-18$ mois.

CONCLUSION : Dans les établissements de soins de longue durée, les taux de Cr mesurés jusqu'à 12 mois auparavant peuvent habituellement servir à évaluer de façon sûre la ClCr. L'utilisation des taux antérieurs de Cr permet de prévoir à l'avance les ordonnances médicales d'amantadine et d'éviter de faire passer de nouveaux tests de $\mathrm{Cr}$ à chaque résident lorsqu'une flambée se produit, ce qui réduit les coûts ainsi que la charge de travail du personnel.

$\mathrm{I}^{\mathrm{n}}$ nfluenza is a major infectious cause of death in the elderly, with institutionalized seniors particularly at high risk. Amantadine hydrochloride is the only drug approved in Canada for prophylaxis of influenza A virus infection. Because amantadine is used more frequently for influenza A outbreak control in long term care facilities (LTCFs), physicians are increasingly called on to prescribe it for residents and to consider the necessity of requesting plasma creatinine $(\mathrm{Cr})$ levels to determine the appropriate amantadine dose.

Amantadine is $70 \%$ to $90 \%$ effective in preventing illness caused by influenza A viruses (1), and reduces the severity and duration of influenza A illness if administered within $48 \mathrm{~h}$ of onset. About $5 \%$ to $10 \%$ of healthy young adults taking amantadine for prophylaxis report difficulty concentrating, insomnia, light-headedness and irritability. These side effects are usually mild and cease shortly after the prophylaxis is stopped but may be more frequent in the older population unless a reduced dosage is used. Serious side effects (eg, marked behavioural changes, delerium, hallucinations, agitation and seizures) have been associated with high plasma drug concentrations. Amantadine is excreted by the kidney unmetabolized. To avoid toxic levels, persons with impaired renal function should receive a lower dose. Creatinine clearance $(\mathrm{CrCl})$ is used to reflect renal function and is estimated from $\mathrm{Cr}$ levels using the following formulas (2):

$$
\text { Male } \mathrm{CrCl}(\mathrm{mL} / \mathrm{min})=\frac{(140-\text { age }) \times \text { weight }(\mathrm{kg})}{\text { serum creatinine }(\mu \mathrm{mol} / \mathrm{L}) \times 0.81}
$$

$$
\text { Female } \mathrm{CrCl}(\mathrm{mL} / \mathrm{min})=0.85 \times \text { male } \mathrm{CrCl}
$$

Table 1 shows amantadine hydrochloride doses recommended by the Canadian National Advisory Committee on Immunization (NACI) by renal status for persons aged 65 years and older.
The aim of the study was to use information readily available in charts to determine whether previous $\mathrm{Cr}$ levels are predictive of the estimated current $\mathrm{CrCl}$ and whether they can help to determine safe amantadine doses based on the NACI guidelines (1).

\section{DATA AND METHODS}

In the spring of 1998, several facilities in Vancouver, British Columbia experienced influenza A outbreaks; Cr levels were measured in many residents in preparation for the titration of amantadine. Two such facilities were selected for this study; an LTCF and an extended care facility (ECF) in which 125 and 166 residents, respectively, had Cr levels measured in March 1998. The study nurse reviewed the charts and extracted data, including $\mathrm{Cr}$ results, weight, age, sex and clearly documented renal disease. The data were entered into a Microsoft Excel (Microsoft, USA) spreadsheet. Logistical regression analysis was performed using SPSS for Windows version 8.0 (SPSS, USA). Multiple $\mathrm{Cr}$ results taken from one person before or after (the March $1998 \mathrm{Cr}$ result) may be related to one another. To reduce autocorrelation, only the closest 'before' and the closest 'after' results were entered into the analysis.

Consent to review a resident's chart was requested from the attending physician of each LTCF resident and the medical coordinator of the ECF. Ethical approval for the study was received from University of British Columbia Clinical Research Ethics Board.

$\mathrm{CrCl}$ was estimated from the March 1998 age, weight and Cr level, and the appropriate amantadine dose was determined; this dose was compared with the amantadine dose estimated for any previous Cr level using the March 1998 age and weight.

$\mathrm{CrCl}$ and amantadine dose were estimated for $\mathrm{Cr}$ results obtained after March 1998 using age and weight at the time $\mathrm{Cr}$ was measured; these were compared with the $\mathrm{CrCl}$ and 
TABLE 1

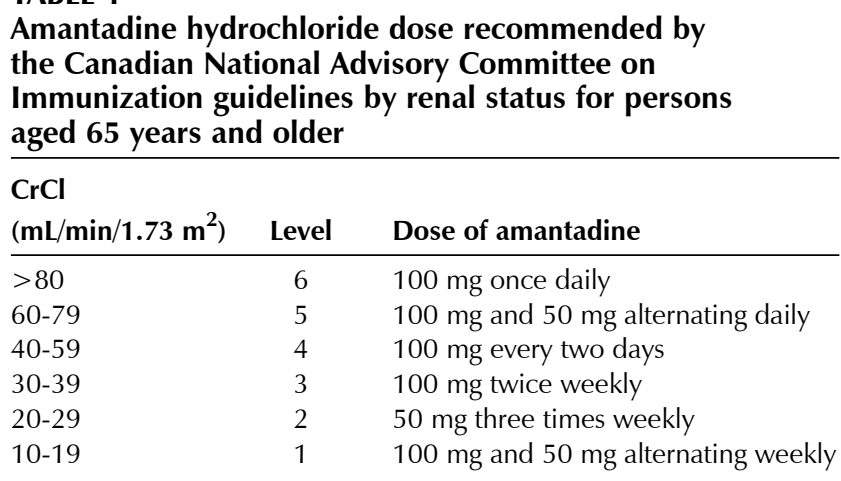

Data adapted from reference 1

amantadine dose estimated from the March $1998 \mathrm{Cr}$ results, and age and weight measured at the time of any later result.

\section{RESULTS}

Ninety-seven of 125 LTCF charts were included. All patients were 65 years old or older; five physicians requested six patient's charts be excluded from the study, and two did not respond despite three requests. Twenty charts with no other $\mathrm{Cr}$ result or in which no $\mathrm{Cr}$ result could be found were excluded.

Sixty-eight of 166 ECF charts were included. Sixteen patients were younger than 65 years old, 82 either had no other $\mathrm{Cr}$ result recorded or the $\mathrm{Cr}$ results were not available. Thus, a total of 165 residents' charts were reviewed; 129 were female and 36 were male. The median age was 86 years old (range 65 to 103 years old).

Only $24 \%$ of patients (39 of 165 ) had $\mathrm{Cr}$ results above normal when measured for amantadine titration in March 1998 (100 $\mu \mathrm{mol} / \mathrm{L}$ for females, $120 \mu \mathrm{mol} / \mathrm{L}$ for males). However, $96 \%$ had a calculated $\mathrm{CrCl}$ below $80 \mathrm{~mL} / \mathrm{min} / 1.73 \mathrm{~m}^{2}(97 \%$ of female patient results and $89 \%$ of male patient results). A reduced amantadine dose would be indicated in these residents based on the NACI guidelines.

In a multivariate model in which the dependent variable had two values (same or lower versus higher dose using NACI guidelines), only one variable was predictive: time since previous $\mathrm{Cr}$ test (odds ratio/month $=0.974$ [95\% CI 0.956 to 0.992]), ie, more recent results were more likely to yield the same or a lower dose. Sex, age, weight, previous $\mathrm{Cr}$ level and facility were not predictive. When only those $\mathrm{Cr}$ tests performed up to 18 months or less previously (179 results) were considered, no variables were predictive.

Figure 1 shows the scatter plot of $\mathrm{CrCl}$ estimated from current $\mathrm{Cr}$ level, weight and age against $\mathrm{CrCl}$ estimated using previous $\mathrm{Cr}$ results, current weight and current age. All results but one indicate the amantadine dose predicted using the previous $\mathrm{Cr}$ level to be within one dose level of that using the current $\mathrm{Cr}$ result. Pearson's correlation coefficients for $\mathrm{CrCl}$ estimated from current $\mathrm{Cr}$ level and estimated from previous $\mathrm{Cr}$ level were: less than six months previously 0.929 , six to 12 months previously 0.974 and 12 to 18

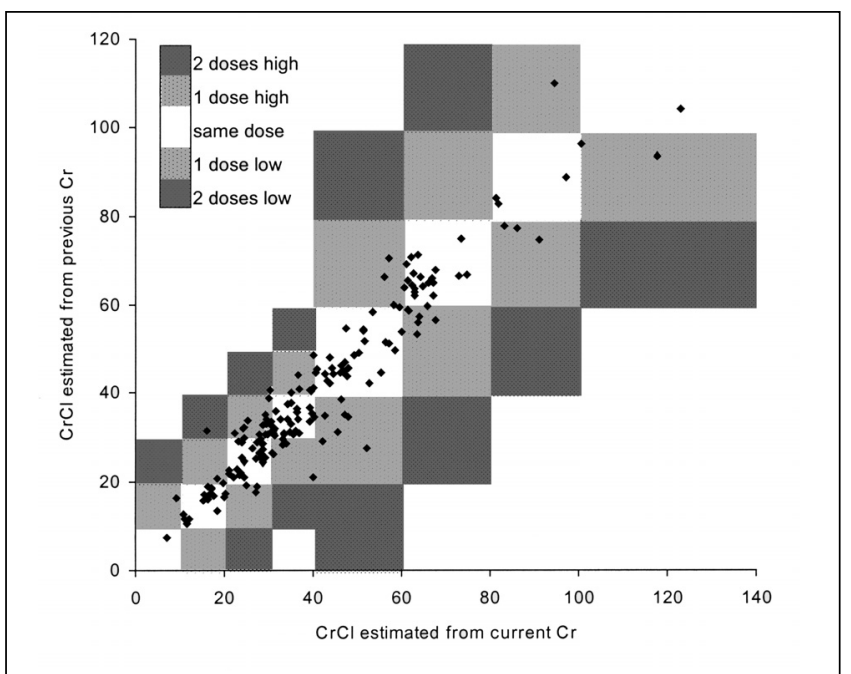

Figure 1) Scatter plot of creatinine clearance $(\mathrm{CrCl}$ $\left[\mathrm{mL} / \mathrm{min} / 1.73 \mathrm{~m}^{2}\right]$ ) estimated from current and previous (up to 18 months) plasma creatinine (Cr) results

months previously 0.952 (all $\mathrm{P}<0.01$, two-tailed). Renal disease or failure was clearly recorded in the charts of only eight residents, despite 21 residents having a $\mathrm{CrCl}$ of less than $20 \mathrm{~mL} / \mathrm{min} / 1.73 \mathrm{~m}^{2}$ when measured in March 1998.

The same or a more conservative amantadine dose was predicted by $81 \%$ ( 29 of 36 ) of Cr results measured less than six months before the March 1998 result and by 97\% (29 of 30 ) of results measured six to 12 months before March 1998. The amantadine dose estimated from a March 1998 Cr level compared with dose estimated from a $\mathrm{Cr}$ level measured within six months after March 1998 predicted a safe dose level $95 \%$ (35 of 37 ) of the time. Thus, a safe dose of amantadine was predicted in $92 \%$ (149 of 162) of residents using a Cr level measured within the previous year, and in $76 \%$ (13 of 17 ) of those using a Cr level measured 12 to 18 months previously.

\section{DISCUSSION}

Amantadine is effective in managing influenza A outbreaks in nursing homes, and its use should be encouraged (3). Physicians and facility staff report concern regarding possible side effects; however, reported side effects are generally mild and transient (4). Under-reporting of side effects may occur in this elderly population given the high proportion of dementia in residential care. The risk of adverse effects should be minimized by dose titration. The development of resistance to amantadine by influenza A virus maybe another concern; however, resistance has not been associated with prophylaxis (5).

Limitations of this study include a possible lack of generalizability. Although sex was not predictive in multivariate logistical regression analysis, only $22 \%$ of residents were male. Most LTCF resident charts were available; however, ECF charts were not readily available for residents who had died or moved, which may have introduced some selection bias. The aim of the study was to use information readily available 
in the charts to determine whether previous $\mathrm{Cr}$ levels are predictive for $\mathrm{CrCl}$ and safe amantadine dose administration. We found that recorded renal disease was a poor indicator of renal failure and recommend that repeat $\mathrm{Cr}$ testing should be performed on anyone in whom a deterioration of renal function may be suspected.

We found that even elderly residents with apparently normal $\mathrm{Cr}$ levels usually required a further adjusted dose of amantadine. A safe dose of amantadine was predicted by $\mathrm{Cr}$ results taken within the previous year in over $90 \%$ of residents. The predicted amantadine dose using previous $\mathrm{Cr}$ results was (with the exception of one result) within one dose level of that using the current $\mathrm{Cr}$ result. Although no trials of systematic low dosing in elderly people have been reported, a few studies suggest that a prophylactic dose of $100 \mathrm{mg}$ daily in those aged 10 to 64 years who have normal renal function may be as effective as the recommended dose of $200 \mathrm{mg}$ daily $(1,6)$. This suggests that the efficacy of amantadine one dose level lower than recommended is likely to be acceptable.

Somewhat unexpectedly, $\mathrm{Cr}$ results taken within six months before March 1998 were not as reliable in predicting amantadine dose as $\mathrm{Cr}$ results taken further before this (six to 12 months before). Similarly, Cr results taken within six months before March 1998 were less reliable predictors of amantadine dose than those taken within six months after. Unfortunately, the reason for testing $\mathrm{Cr}$ levels was not easily determined from chart review. However, its clinical indication may be a sign of acute disease and ensuing renal function deterioration, particularly where repeat tests within a short period were sought.

Time was not predictive for results taken within 18 months, suggesting that remeasuring of $\mathrm{Cr}$ may not be necessary if a result is already available from within this period.
Further study is necessary to enable conclusions to be made regarding the safety of using creatinine results from 12 to 18 months previously to estimate amantadine dose; the sample size in our study was very small.

\section{CONCLUSIONS}

In facilities for elderly people, using a dose of amantadine based on $\mathrm{Cr}$ results taken within the previous 12 months seems appropriate based on our results and may facilitate efficient outbreak control. It permits advance preparation of doctor's orders for amantadine prophylaxis and avoids the need to repeat $\mathrm{Cr}$ testing on every resident at the time an outbreak occurs, thus potentially reducing the time and cost for effective control.

ACKNOWLEDGEMENTS: The authors acknowledge the assistance and cooperation of the staff of facilities and the attending physicians of the residents.

\section{REFERENCES}

1. National Advisory Committee on Immunization. Statement on influenza vaccination for the 2001-2002 season. Can Commun Dis Rep 2001;27:1-36.

2. Cockcroft DW, Gault MH. Prediction of creatinine clearance from serum creatinine. Nephron 1976;16:31-41.

3. Patriarca PA, Arden NH, Koplan J, Goodman RA. Prevention and control of type A influenza infections in nursing homes Benefits and cost of four approaches using vaccination and amantadine. Ann Intern Med 1987;107:732-40.

4. Buxton J, Daly P, Bigham M. Influenza outbreaks in Vancouver long-term and extended-care facilities, January to April 1998. BC Med J 1999;41:128-30.

5. Monto A. Guidelines for the clinical use of antivirals In: Nicholson KG, Webster RG, Hay AJ, eds. Textbook of Influenza. Oxford: Blackwell Science Ltd, 1998:508-9.

6. Aoki F. Amantadine and rimantadine. In: Nicholson KG, Webster RG, Hay AJ, eds. Textbook of Influenza. Oxford: Blackwell Science, 1998:457-76. 


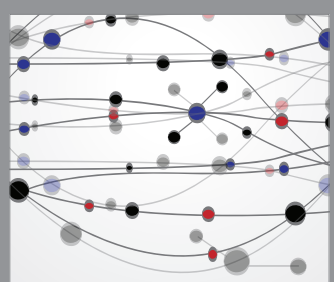

The Scientific World Journal
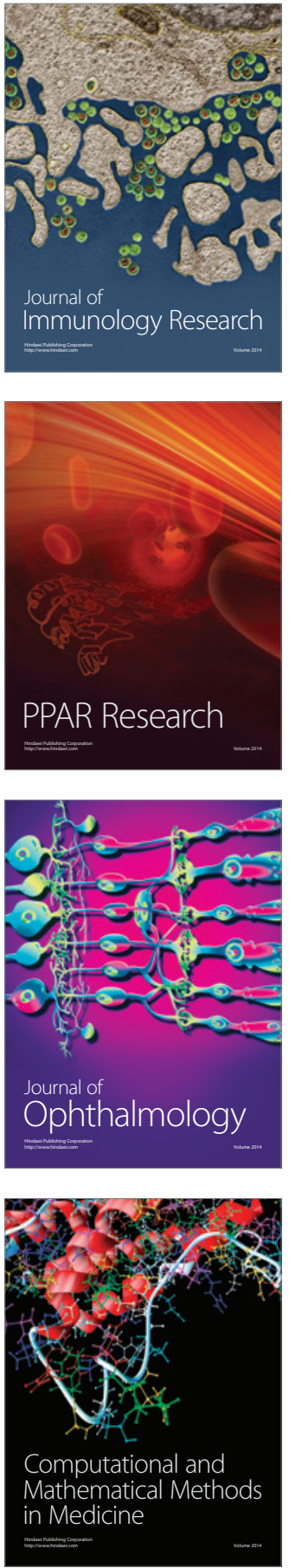

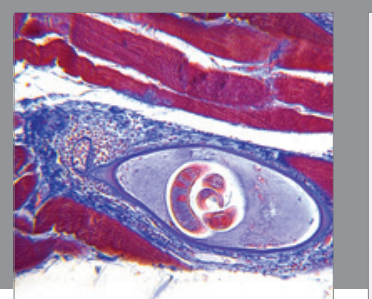

Gastroenterology Research and Practice

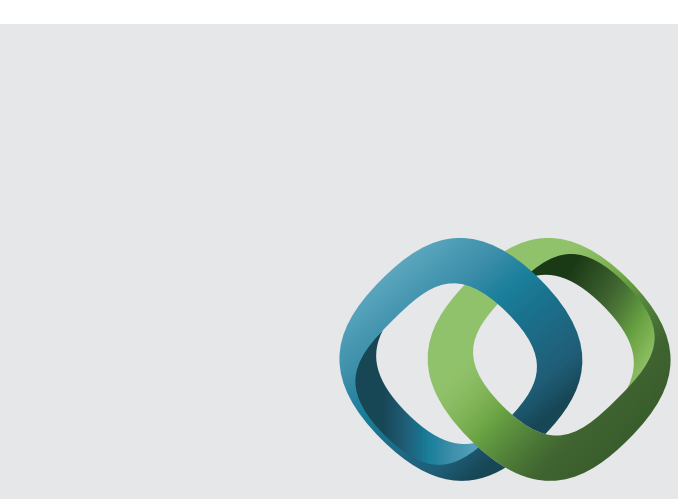

\section{Hindawi}

Submit your manuscripts at

http://www.hindawi.com
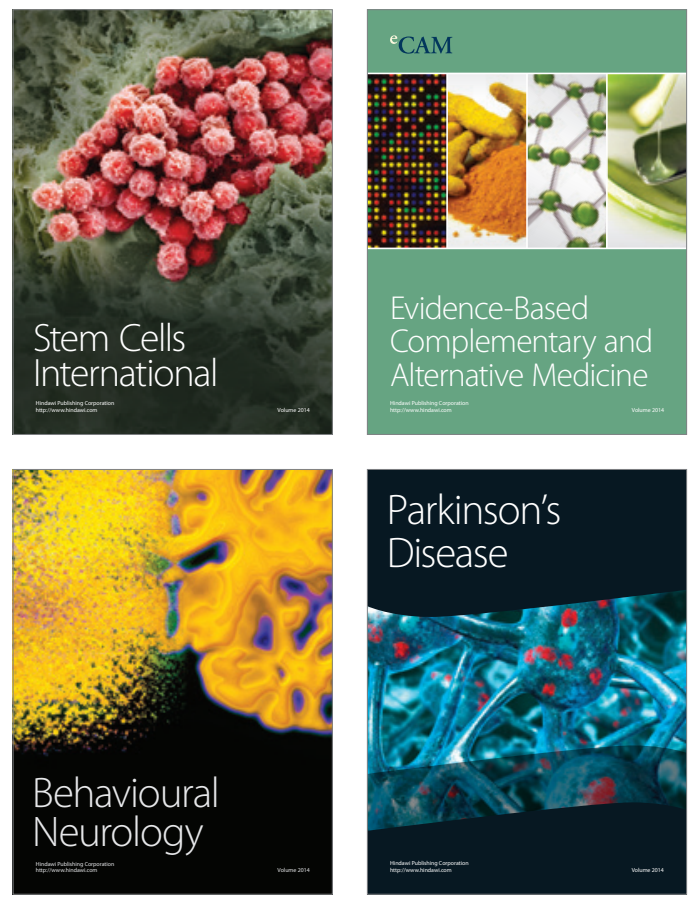
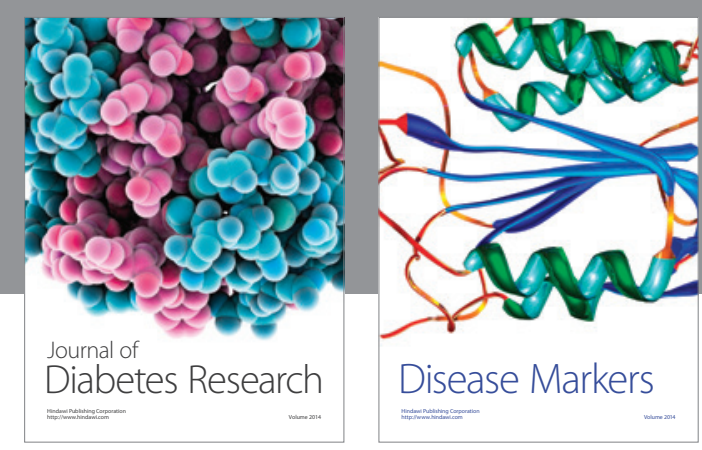

Disease Markers
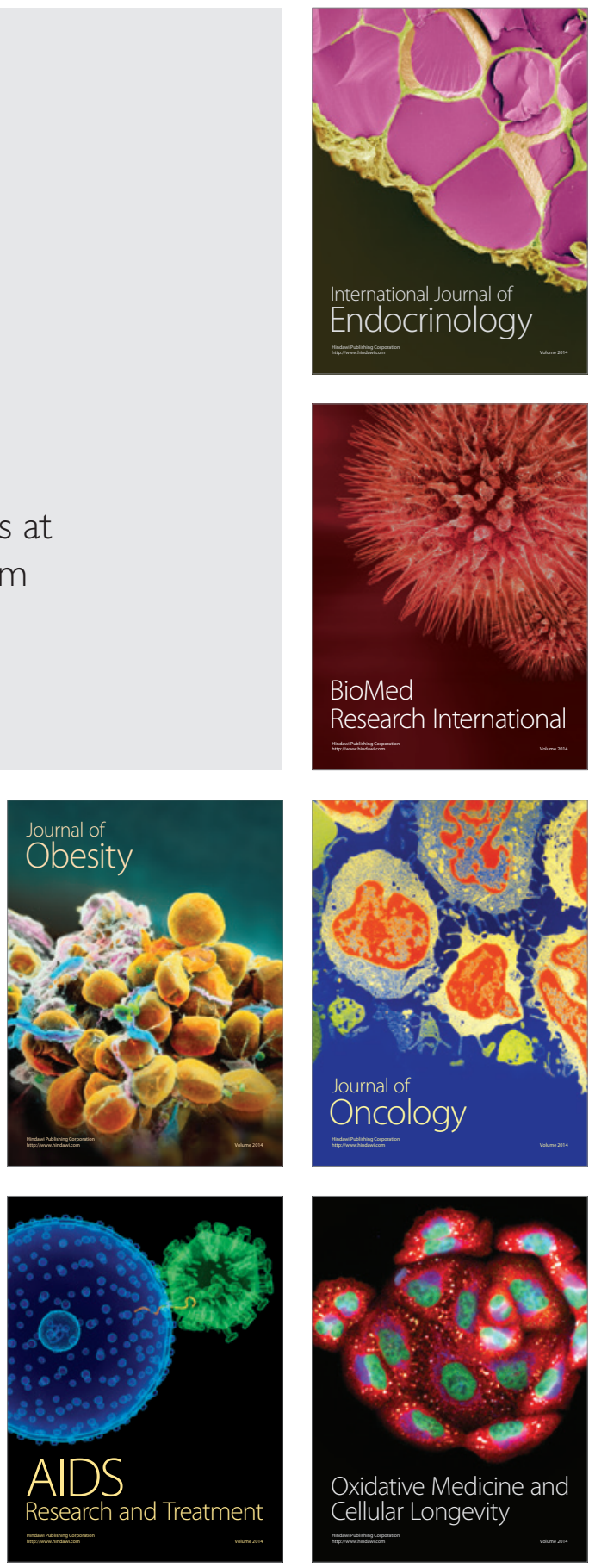